been high with particulate or liquid embolic media. Rather, we attempted to reduce blood flow as much as possible to facilitate operation.

Complete surgical resection of a mediastinal AVM is rarely possible. Anti-angiogenic therapy, corticosteroid treatment, interferon administration, and intralesional sclerotherapy have not been helpful. ${ }^{4}$ A carefully planned program of embolization to reduce flow, followed by surgical excision, was effective in controlling the first patient's tracheal disease. An earlier aggressive approach for the second patient, when the tracheal lesion also appeared more localized, might have produced a similar long-term palliative result.

\section{References}

1. Hirata S, Ogino K, Saji K. A case of mediastinal arteriovenous fistula. Classification on thoracic arteriovenous fistula and review of the literature. Nihon Kyobu Shikkan Gakkai Zasshi. 1975;13:477-81.

2. Hammerer I, Stampfel G. Ausgedehntes haemangioma racemosum des Mediastinums mit Zwerchfellparese. Ein fallbericht und beitrag zur differentialdiagnose des arteriovenösen aneurysmas im thoraxbereich. Padiatr Padol. 1977;12:63-72.

3. Lunde P, Sörlie D, Bolz KD, Eide TJ. Huge arteriovenous malformation in the mediastinum. Scand J Thorac Cardiovasc Surg. 1984;18:75-80.

4. Fishman SJ. Vascular anomalies of the mediastinum. Semin Pediatr Surg. 1999;8:92-8.

\title{
Bronchotomy in the treatment of a low-grade bronchial mucoepidermoid carcinoma in a child
}

\author{
George Vaos, MD, PhD, ${ }^{a}$ Nick Zavras, MD, PhD, ${ }^{a}$ Kostas Priftis, MD, PhD, ${ }^{b}$ Catherine Micahil-Strantzia, $\mathrm{MD}^{\mathrm{c}}$ and \\ George Antypas, MD, PhD, ${ }^{d}$ Athens, Greece
}

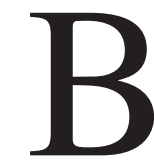

ronchial mucoepidermoid carcinomas in children are the rarest variant of bronchial adenomas, and they generally behave in a benign fashion. ${ }^{1}$ Until 2000 , only 54 cases of proved bronchial mucoepidermoid carcinoma in children younger than 15 years had been reported in the literature. ${ }^{2}$ Fifty of these were low-grade carcinomas with a benign clinical course. Because of the predilection for the main bronchus, bronchoplastic techniques for complete surgical resection of such low-grade lesions are the recommended therapy, allowing preservation of the maximum amount of lung parenchyma. ${ }^{2}$ We describe a low-grade mucoepidermoid carcinoma of the left main bronchus in a 6-year-old boy in whom a complete removal of the tumor by means of bronchotomy and extirpation was performed, with excellent results.

\section{Clinical Summary}

An otherwise healthy 6-year-old boy was referred to us with a recent history of productive cough and hemoptysis. He had recurrent episodes of pneumonia for the past month. On auscultation,

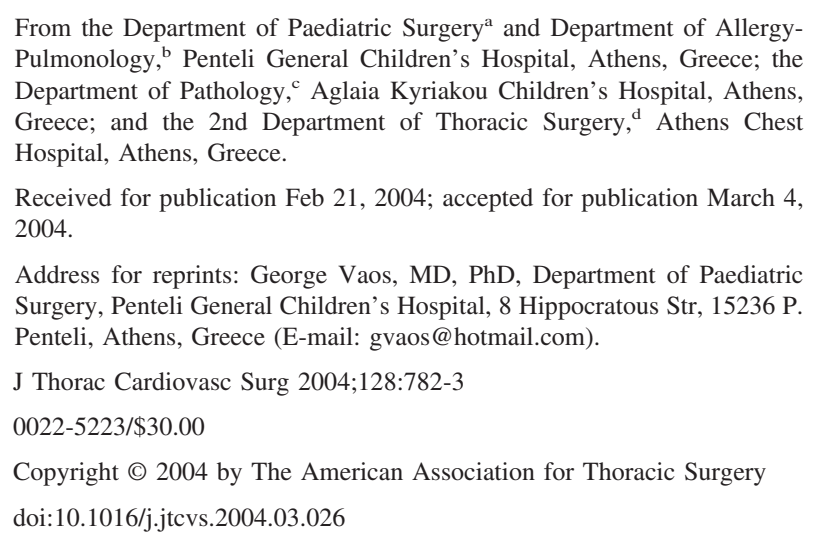

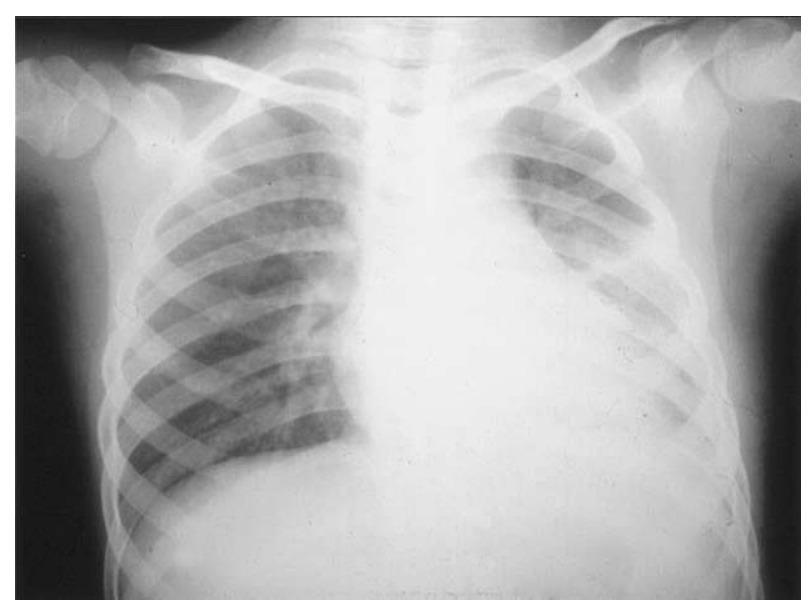

Figure 1. Chest $\mathrm{x}$-ray film on admission: posteroanterior view showing a consolidation atelectasis of the left lower lobe.

expiratory wheezing on the upper left lung field was observed. A chest $x$-ray film showed an area of increased density in the left lower lobe, suggesting a typical complete lobar atelectasis (Figure 1). Computed tomography showed a solid endobronchial tumor mass blocking the left main bronchus. Subsequent fiberoptic bronchoscopy revealed a small polypoid mass arising from the distal end of the left main bronchus and partially obstructing the lumen of the left lower lobe bronchus. Transbronchial biopsy of the mass suggested a mucoepidermoid carcinoma.

An unexpectedly prolonged hypoxia during the operation changed our plans for a right lower lobe sleeve lobectomy because our patient was unable to tolerate a long operation. Therefore a transverse bronchotomy of the left main bronchus was performed, and the tumor was completely removed because it was technically possible. The regional bronchopulmonary lymph nodes were re- 
moved for histology. The tumor was a whitish pink, friable mass and measured $0.7 \times 1.0 \mathrm{~cm}$. Microscopic examination revealed a mixed picture of epidermoid and glandular elements scattered throughout a fibrous stroma. Epidermoid cells and sheets of intermediate cells were intimately admixed with the glandular component. The glands were lined with mucus-rich goblet cells and nonmucus-secreting columnar cells surrounding pools of mucus (Figure 2). A histopathologic diagnosis of low-grade mucoepidermoid carcinoma was made. All the regional lymph nodes removed were negative for tumor infiltration.

The patient's postoperative course was uneventful, and the child was discharged on the eighth postoperative day. He has been followed for 2.5 years with repeated bronchoscopic examinations without any evidence of tumor recurrence.

\section{Discussion}

Parenchyma-sparing bronchoplastic procedures are widely used in adults with benign bronchial stenosis and low-grade malignancies of the airway when anatomically suited lesions exist, allowing maximal preservation of lung function. ${ }^{3}$

The malignant potential of bronchial mucoepidermoid carcinoma in pediatric patients remains controversial. ${ }^{1,2}$ Until now, only 55 cases of that type of tumor have been reported in children less than 15 years of age. Fifty-one tumors were histologically classified as low-grade lesions.

Because high-grade malignancy is rare and the tendency of this tumor to metastasize is low, conservative resection incorporating all disease tissue is the recommended therapy in children. ${ }^{4}$ Sleeve resection of the involved bronchus should be attempted. However, when this is not technically possible, segmental resection or lobectomy will be necessary for complete removal of the lesion. A pneumonectomy in this age group should be avoided if possible to prevent the later development of devastating complications. Extirpation of the tumor by means of bronchotomy has been described before in a child. ${ }^{5}$

The patient described in this report had a mass located at the distal end of the left main bronchus causing atelectasis of the left lower lobe. Excision of the left lower lobe along with a segment of the main bronchus could have been attempted. Instead, because of the inevitable anesthetic problems during the operation, the tumor was completely extirpated by means of bronchotomy of the left main bronchus. Removal of the tumor by using bronchotomy is less than optimal because complete resection of the tumor cannot be ensured. We speculate that in the case presented here the bronchotomy was performed relatively early because the symptomatology started 4 weeks before admission. The mass was small and located in the left main bronchus. Therefore it was feasible to remove the tumor completely. It appears that complete resection of the tumor by means of bronchotomy has been successfully achieved in this particular case because no local recurrence has been identified 2.5 years after the procedure.

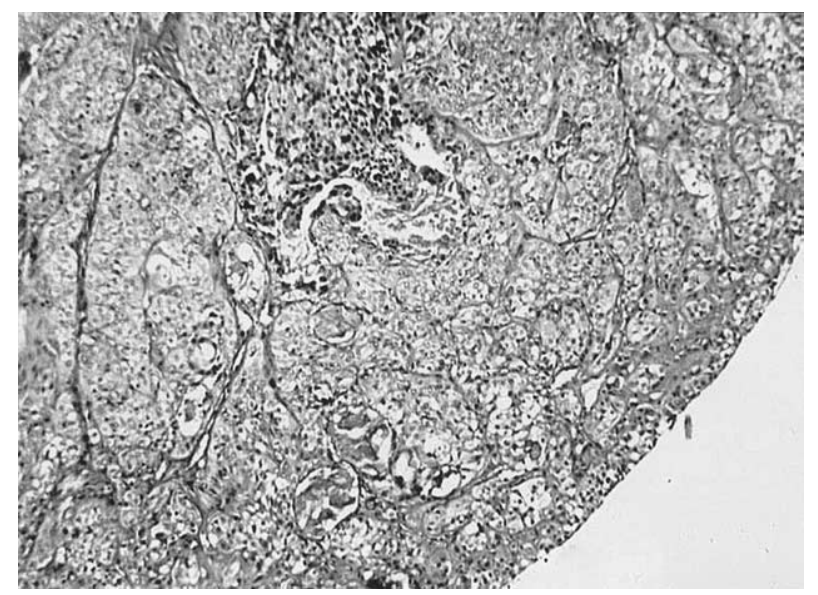

Figure 2. Low-grade mucoepidermoid carcinoma with solid sheet-like areas of epidermoid cells (top middle) and mucuscontaining glands (bottom middle). (Hematoxylin and eosin, original magnification $100 \times$.)

This is only the second reported patient with a bronchial mucoepidermoid carcinoma who underwent a successful bronchotomy for tumor resection. In the first case the low-grade tumor was located in the proximal end of the right main bronchus. The patient was disease free 2 years after bronchotomy. ${ }^{5}$

The usually low-grade bronchial mucoepidermoid carcinomas make conservative bronchoplastic procedures a preferred and often adequate therapeutic approach. Bronchotomy and resection of the tumor should be reserved for small lesions localized in the main bronchus that are definitely of low grade. A careful follow-up of such cases through periodic bronchoscopic examinations is advisable.

\section{References}

1. Granata C, Battistini E, Toma P, Balducci T, Mattioli G, Fregonese B, et al. Mucoepidermoid carcinoma of the bronchus: a case report and review of the literature. Pediatr Pulmonol. 1997;23:226-32.

2. Dinopoulos A, Lagona E, Stinios I, Konstantinidou A, Kattamis C. Mucoepidermoid carcinoma of the bronchus. Pediatr Hematol Oncol. 2000;17:401-8.

3. Bueno R, Wain JC, Wright CD, Moncure AC, Grillo HC, Mathisen DJ. Bronchoplasty in the management of low-grade airway neoplasms and benign bronchial stenoses. Ann Thorac Surg. 1996;62:824-9.

4. Gaissert HA, Mathisen DJ, Grillo HC, Vacanti JP, Wain JC. Trachiobronchial sleeve resection in children and adolescents. J Pediatr Surg. 1994;29:192-7.

5. Deschildre A, Sardet A, Brouard J, Delaisi B, Boussard L, BocconGibod L, et al. Carcinomes mucoépidermoïdes bronchiques: à propos de trois observations. Arch Pediatr. 1996;3:689-93. 